\title{
The Journey of International Fellows: Have you been to America?
}

\author{
Fernanda Erthal, $M D{ }^{a}$ and Rob Beanlands, $M D^{a}$ \\ ${ }^{a}$ Division of Cardiology, Department of Medicine, National Cardiac PET Centre, University of \\ Ottawa Heart Institute, Ottawa, Canada
}

Received Oct 4, 2015; accepted Oct 4, 2015

doi: 10.1007/s12350-015-0307-0

\author{
"It takes a village to raise a child" -African \\ proverb \\ It takes team to train a fellow!
}

At the recent meetings of ASNC in Washington DC and ICNC in Madrid Spain, I was reminded of the power of networking: a chance to share with colleagues, learn the latest approaches, new evidence and developments, reassurance that we all have similar challenges and also the camaraderie, much of which stems from our days as fellows. This year I was particularly struck and moved by seeing past fellows (our program and others) who have succeeded and are now on the podium, writing papers, directing labs, even editing journals! This gave me to reflect on the journey of fellowship to investigator particularly for those of us from outside the US. Why is having 'Been to America' or now-a-days 'Been to North America' or 'Been to Europe' such a right of passage? Why do we engage and value this international exchange?

The majority of new knowledge in cardiovascular care has emerged from academic centers particularly in the so-called 'developed world.' Research requires resources. These resources include funding, infrastructure, human capacity, skill, and time. Societies must carry a view that it is a long-term investment whose benefits may not be realized for years to come. In Jared Diamond's book "Guns, Germs and Steel,", he identifies that there are regions in the world with more 'cargo' that reflect many environmental forces beyond our control. He also notes that innovation is driven in part by necessity and in part by curiosity. Societies with limited resources must focus more on immediate essentials and are less likely to lead advancements. At

\footnotetext{
Reprint requests: Rob Beanlands, MD, Division of Cardiology, Department of Medicine, National Cardiac PET Centre, University of Ottawa Heart Institute, Ottawa, Canada; rbeanlands@ottawaheart.ca J Nucl Cardiol 2015;22:1161-2.

$1071-3581 / \$ 34.00$

Copyright (C) 2015 American Society of Nuclear Cardiology.
}

the same time, societies where mutual exchange occurs can accelerate advancement for each other. Finally, he points out that while resources may vary, intelligence and curiosity are ubiquitous. If resources are provided, advances can occur anywhere. When we enable international fellowship, we enable an exchange that will augment advances in medicine (and all fields) and patient care in our own countries and around the world.

So what of the current environment for fellows wanting to pursue academic careers at home or abroad? A recent survey by the American College of Cardiology (ACC) suggested that $7-10 \%$ of early career cardiologists are 'academic.' Among the top reasons for an academic career path were the academic environment, desire to teach, desire to do research, and the ability to "do greater good.", The most important contributing factors to success were onsite mentoring, institutional resources, institutional commitment, and connections with collaborators. ${ }^{2,3}$ The mentor influence, researchoriented programs, and research protected time have direct impact on academic career choice and success. ${ }^{4,5}$ The most important challenge, on the other hand, for stable academic careers, not surprisingly, is diminishing research funds from government, NGOs, and industry. As per the quote that leads this editorial, it takes a team to train a fellow. This team includes the immediate team of the site institution but also the community team in the field as a whole. As such not only do we have an obligation locally but also globally to create vehicles for fellows success through mentoring, creating opportunities for presentation and publication and advocating for increased funding and support for young investigators careers which is clearly an investment in our future.

But we must not forget the personal sacrifice that fellows make when they move to new cities, environments, and countries. How many of us from abroad have disaster stories of our transitions from our home countries to the USA for fellowship? For myself, we faced too many perils en route to mention, almost comical now in retrospect, but nerve-wracking at the time and 
culminating with my loving wife saying "this better be worth it." Well it was! But the challenges of transition for this Canadian pale in comparison to what international fellows from other continents experience. Here is a recent international fellow's experience:

Why does a young medical doctor decide to give up everything in their own country to do a fellowship in North America or Europe? The curiosity for what is new and unexplored is what catalyzes innovation that can change the world [similar to what motivates all fellows as per the ACC survey ${ }^{2}$ ]. The possibility to move to a new country, study in the best universities, work together with international leaders, see with your own eyes how new knowledge is discovered - and perhaps be the next one to discover - is the dream of many trainees.

The decision is not easy. After 8 to 12 years of training in one's own country to sacrifice even more for medicine? Why not stay home: your country, your family, your friends, your university, your hospital, your language, your culture? You are known and respected. You have already had a long hard journey to reach this stage. It is painful to leave everything behind for this new experience 'abroad'.

You must start again almost from scratch which you don't fully realize until you get there! You must learn a new language, idioms, jargon, how to prescribe the most simple medication or order a test, how to walk and talk in the new hospital, how to be the "foreigner"! What of the steps before: acceptance at the university, documentation, visa (oh the Visas!), choose a neighborhood, find an apartment, which phone/internet, where to shop and bank, buy a car, get a license, health insurance! It is as if you do not exist until all this is done. No book, website, you-tube video can prepare you for this transition. But it is worth it! Starting a new fellowship in North America is amazing! You are in touch with everything about which you have dreamed! Its easier to access new therapies, use novel equipment, participate in research, be part of the academic world! All countries have geniuses and wonderful teachers, but we do not all have opportunities that exist in North America and Europe. Fellowship abroad helps spread new knowledge and know-how to all corners of the globe. The knowledge disseminates, people integrate and we make each other better.

Soon the new fellows among us will have seen several hundred patients, read several hundred scans, presented their first oral presentation, and published their first original manuscript (maybe in the Journal of Nuclear Cardiology ${ }^{\circledR}$ !). Not only did they survive but they thrive. Whether they return to their home country or stay in their new land, they carry with them the clinical and research expertise that will become tomorrow's innovations and more than this they have a global perspective. They will pass this on to the next generation of fellows as the cycle of academic life continues. A process that spreads wider in the globe with every cycle as the world becomes smaller. Yes 'it is worth it'!

We must remember that our fellows and trainees have more knowledge than we had. Most are smarter than we are and will accomplish more than we have. International fellows are an investment in the global future of the field. It is our collective responsibility to enable their success. The Journal of Nuclear Cardiology represents one of several enablers that the community can provide to ensure success of our young colleagues. ASNC, as evidenced by the recent meeting, is a strong enabler of fellows and young investigators-an emphasis that must continue and further grow and adapt to the changing environment around us. May we provide them all the wisdom that we can and clear the path to success for their sake, our sake, and for patients and people around the world.

\section{References}

1. Diamond J. Guns, germs and steel. New York: Norton and Company Limited; 1999.

2. Tong CW, Ahmad T, Brittain EL, Bunch TJ, Damp JB, Dardas T, et al. Challenges facing early career academic cardiologists. J Am Coll Cardiol 2014;63:2199-208.

3. Marbán E, Braunwald E. Training the clinician investigator. Circ Res 2008;103:771-2.

4. Borges NJ, Navarro AM, Grover A, Hoban JD. How, when, and why do physicians choose careers in academic medicine? A literature review. Acad Med 2010;85:680-6.

5. Lyle JL, Vandergrift JL, Hinkel JM, Lepisto EM, Cortazzo KA, Sherman S, et al. Influential factors for post-fellowship career decision-making: An NCCN survey. Natl Compr Cancer Netw 2012;10:969-74 